\title{
HIV/AIDS Risk Behaviour in South African Schizophrenia Patients
}

\author{
Risque du VIH/SIDA chez des patients Sud Africain souffrant de la Shizophrénie.
}

\author{
L. Koen, S. V. Vuuren, D. J. H. Niehaus, R. A. Emsley
}

\begin{abstract}
BACKGROUND: Initially the risk of HIV in people with severe mental illness (SMI) was grossly underestimated but comparisons with the general population have in fact revealed higher infection rates in this particular group. Not only are patients with SMI sexually active but it has also been demonstrated that this group and especially patients with schizophrenia are less knowledgeable about HIV risk behaviours than the general population. Currently no data concerning the participation in and knowledge of HIV/AIDS risk behaviours by South African schizophrenic patients is available.
\end{abstract}

METHODS: Patients with schizophrenia and a control-group were recruited from community clinics in the Western Cape, South Africa, whereafter 43 from each group were matched (race, age, sex). The patient group was subjected to a structured clinical interview and both groups completed the AIDS Risk Behaviour Assessment (ARBAQ) and Knowledge (ARBKQ) Questionnaires.

RESULTS: Comparatively, significant knowledge deficits could be demonstrated for the patient group in overall terms $(p<0.001)$ as well as for five specific items (all $p<0.05$ ) on the $A R B K Q$. Furthermore, $10 \%$ of the patients believed that the depot antipsychotic injection placed individuals at risk for contracting HIV. Both groups also admitted participation in various high risk sexual behaviours.

CONCLUSION: Our results suggest that patients with schizophrenia should be a target group when developing AIDS prevention programmes. In order to identify particularly at risk individuals, a comprehensive risk behaviour assessment should form part of the psychiatric interview. WAJM 2007; 26(1): 2 - 6 .

Keywords: Schizophrenia, Risk behaviour knowledge, HIV.

\section{RESUMÉ}

Contexte: Le risque du VIH chez des individus avec des problemes mentaux très sévère était grandement négligé, mais a comparer avec la population generale, presente de taux d'infections trop élevé. Non seulement ces patients souffrant de la shizophrénie manquent de connaissance adequate du VIH comparativement à la population normale. Presentement, il n'y a pas de rapport concernant la participation et la connaissance des comportement à risque du VIH/SIDA par le les patients shizophrénique sud-Africain.

Méthods: Les patients de la shizophrenie et des sujets normaux étaient sélectionés des cliniques communautaires dans l'Ouest du Cape, Afrique du Sud, 43 de chaque group étaient groupés en fonction de la race, $l$ 'âge et le sex. Le groupe des patients était soumis à un interview clinique bien structuré et les deux groupes ont rempli un questionaire du test de comportement à risque du SIDA.

Résultats : Comparativement au groupe des sujets normaux, les patients ont démontré un manque de connaissance $(p<0.001)$ de facon générale ainsi que pour 5 élements spécifiques dans le questionnaire. En plus, $10 \%$ des patients croyait que les injections antisychotique les exposent au VIH. Les deux groupes ont aussi admit s'associer aux comportements à haut risque.

Conclusion: Nos résultants suggèrent que les patients de shizophrénie doivent être consideré dans les programmes de prévention du SIDA. Afin d'identifier particulierèment les individus à risque, un test compréhensif des comportements à risque doit faire partie intégrale des interviews psychiatriques. WAJM 2007; 26(1): $2-6$.

Mots Clés: shizophrénie, comportement à risque, connaissance.

Department of Psychiatry, University of Stellenbosch, South Africa

Correspondence:Dr. Liezl Koen, P. O.Box 19063, Tygerberg 7505, South Africa. E-mail: liezlk@sun.ac.za

Abbreviations:AIDS Acquired immune deficiency syndrome; ARBAQ, AIDS Risk Behaviour Assessment; ARBKQ, AIDS Risk Behaviour Knowledge Questionnaires; HIV , Human immune deficiency virus; SMI, severe mental illness. 


\section{INTRODUCTION}

Few would argue that one of the greatest health crises the world is facing today is that of HIV/AIDS. This epidemic has claimed nearly 20 million lives in the last two decades and it is estimated that 40 million people are now living with HIV/ AIDS, $95 \%$ of them in developing countries. ${ }^{1}$

In South Africa, the magnitude of the pandemic remains frightening. Using the Actuarial Society of South Africa (ASSA) 2002 model, it has been estimated that just over 5 million South Africans were HIV positive in 2004, with the estimated deaths due to AIDS in 2010 between 300000 and $450000 .^{2}$ However, the situation is not only one of doom. In the past 5 years, far more efficacious treatments haves been developed, making it all the more important for HIV infection to be detected and treated early. ${ }^{3}$

Popular misconceptions such as that the severely mentally ill lack the skills to form intimate relationships or have less need to do so and that they engage in sexual activities less frequently either as a result of their mental illness or its treatment, led to the risk of HIV infection in this population group to be grossly underestimated during the first decade of the AIDS epidemic. ${ }^{4}$ In fact, several studies have shown a much higher HIV infection rate among persons with serious mental illness compared to the general population. Sullivan et $\mathrm{al}^{3}$ did a Medline search of literature in the United States and found 12 studies which showed seroprevalence rates of between $5 \%$ and $23 \%$ compared to $0.3 \%$ to $0.6 \%$ in the general population. Currently no South African data exist concerning infection rates in this particular population.

In their meta-analysis of 52 studies reporting on HIV risk behaviours in the severely mentally ill, Meade and Sikkema ${ }^{5}$ found that the majority of adults with severe mental illness were sexually active and many engaged in risk behaviors associated with HIV transmission (e.g., unprotected intercourse, multiple partners, injectable drug use). Even where studies have suggested that a smaller portion of patients with severe mental illness are sexually active compared to the general population, it has been demonstrated that those who are active tend to engage in higher risk sexual behaviour, with specifically schizophrenia sufferers as a group exhibiting a much higher risk for contracting HIV disease. ${ }^{6}$

In patients with schizophrenia, both positive and negative symptoms affect the ability to sustain long-term relationships and it is well known that neuroleptic treatment is associated with sexual dysfunction. ${ }^{7}$ However, these problems do not necessarily eliminate the desire for sexual contact or render the patient sexually inactive. The high-risk activity might in part be due to the chronic mental illness itself, which is often associated with poor judgement and impulsiveness. High rates of drug and alcohol use may also impair an individual's ability to protect him/herself in high-risk situations. ${ }^{3}$

A number of studies have focussed specifically on the levels of HIV/AIDS risk behaviour knowledge in patients with severe mental illness. Ninety-five subjects (54\% with a diagnosis of schizophrenia) were subjected to a 10 -item true-false test by Kalichman et $\mathrm{al}^{8}$ to assess knowledge of AIDS information. A number of basic presumptions such as "most people who have the AIDS virus are sick within a few weeks" and "a person cannot get the AIDS virus by sharing kitchens and bathrooms with someone who has AIDS" were answered incorrectly by more than $50 \%$ of the participants although better results were achieved with items specifically relating to the sexual transmission of HIV. Kelly et $\mathrm{al}^{9}$ administered a questionnaire involving knowledge of HIV risk to their group of 60 chronically mental ill subjects and concluded that there were substantial deficits in risk knowledge among these patients when compared to the general population.

No studies focusing on the presence or lack of HIV/AIDS knowledge or the extent of their participation in high risk sexual behaviour have previously been conducted on a South African schizophrenia population. Taking into account that South Africa currently has a population HIV-prevalence rate of $11 \%^{2}$ (one of the highest in the world) clearly a an urgent need for such data exist. Our study was therefore the first of its kind and the primary hypothesis was that significantly lower levels of HIV/AIDS risk behaviour knowledge in schizophrenia sufferers (vs. controls) would be demonstrated in our group. As a secondary hypothesis it was further postulated that the popular belief that subjects who suffer from serious mental illness engage in sexual activities less frequently and therefore are not a highrisk group for HIV infection would be disproved.

\section{MATERIALSANDMETHODS}

Subjects: Sixty-seven subjects at various stages of schizophrenic illness (criteria as defined in DSM-IV) ${ }^{10}$ and a hundred controls were recruited (as part of a larger ongoing genetic study) from the Associated Psychiatric Hospitals Catchment Area in the Western Cape, South Africa. Forty-three subjects could be matched for race, sex and age (within 5 years) and therefore qualified for inclusion. Participants in both groups were between 18-65 years (extremes included) and the control group consisted of volunteers recruited from amongst members of the public that were attending community health clinics in the Northern and Southern Metropole Area of Cape Town for a medical visit of any kind.

Procedures and Measures. Each participant in the schizophrenia group was subjected to the standardized Diagnostic Interview for Genetic Studies (version 2.0) (DIGS) ${ }^{\text {III }}$ in English, Afrikaans, and/or Xhosa (with the help of an interpreter). The DIGS is a clinical assessment tool designed for diagnosing major mood and psychotic spectrum disorders. Furthermore, the AIDS Risk Behaviour Assessment Questionnaire (ARBAQ) and the AIDS Risk Behaviour Knowledge Questionnaire (ARBKQ) ${ }^{9}$ were administered to both groups.

The ARBAQ is a tool used by researchers to assess the sexual high-risk situations patients might encounter or engage in. The scale was adapted by the MRCUnit on Anxiety Disorders (affiliated to the Department of Psychiatry, University of Stellenbosch) from similar scales ${ }^{12,13}$ previously used. The ARBKQ developed by Kelly consists of 11 truefalse items measuring the participants' 
practical understanding of risk behaviour and risk reduction steps. The original ARBKQ ${ }^{14}$ consisted of 40 true - false items and was normed and validated on populations other than the chronically mental ill.

The adapted 11 items scale is thought to tap the knowledge areas most pertinent to the risk characteristics of a chronic mentally ill population. In light of the focus on needle sharing in AIDS risk education strategies and the important role depot medication plays in the treatment of schizophrenia in South Africa, an item regarding the risk of contracting AIDS via the depot injection was added to the ARBKQ.

Statistical Analysis: The demographic data of the control and patient groups were descriptively analysed using the SPSS software package. Descriptive statistics for each of the individual items on the questionnaires were done. The total number of correct responses on the ARBKQ were calculated for each subject and descriptive statistics performed. Subsequently either student t-test or chisquare analyses, depending on the data structure, were done to test for associations between demographic variables and total correct number of correct responses and individual item results. Average values are given as mean (SD).

Ethical Considerations: The study was approved by the committee for Human Research of the University of Stellenbosch and their ethical guidelines were strictly adhered to at all times.

\section{RESULTS}

Each group consisted of 43 subjects, 13 female and 30 male, all belonging to the Xhosa ethnic group. There was no statistical difference between the age at interview of the patient group and the control group [(33.95(10.8) vs $34.47(10.4)$ years].

The AIDS Risk Behaviour Assessment Questionnaire consists of ten questions relating specifically to participants' sexual histories and involvement in possible high-risk sexual behaviours. Table 1 contains the full questionnaire and results.
All values reported are in patients vs controls format. There was no statistically significant difference between the ages at which the different groups had their first sexual experience - $[16.5$ (2.6) vs. $16.2(5.3) p=0.674]$. Neither was there a difference for the choice of partner for the first experience - regular partner/spouse (90.7\% vs $97.7 \%$ ), casual partner (7\% vs $2.3 \%$ ) or being raped ( $2.3 \%$ vs $0 \%$ ). Only $46.5 \%$ of the patient group had had sex in the last 6 months compared to $86 \%$ of the control group $(\mathrm{p}<0.0001)$. However, there was no significant difference in the number of partners during the previous six months [1.05 (0.59) vs 1 (1.1), partners $p=0.79]$.

With regard to high risk situations encountered, although no statistically significant difference could be demonstrated-between the groups, some of the patients did admit to having had sex in exchange for money $(n=3)$, drugs $(n=1)$ or a place to stay $(n=1)$. None of the control group admitted to engaging in these high-risk behaviours. Two patients also admitted to having sex with a partner who had used intravenous drugs compared to none of the control group. None of the other high risk situations reached statistically significant differences. Only a quarter (25.6\%) of both groups had used a condom at their last sexual encounter.

Table 1: Responses to AIDS Risk Behaviour Assessment Questionnaire.

\begin{tabular}{|c|c|c|}
\hline & \multicolumn{2}{|c|}{ Percent that answered yes } \\
\hline & Patients & Controls \\
\hline Do you currently have a partner/spouse? & $81.4 \%$ & $88.4 \%$ \\
\hline Have you had sex in the last 6 months? & $46.5 \%$ & $86.0 \% *$ \\
\hline Did you use a condom with your last sexual encounter? & $25.6 \%$ & $25.6 \%$ \\
\hline \multicolumn{3}{|l|}{ Have you had sex in exchange for: } \\
\hline Money? & $7 \%$ & $0 \%$ \\
\hline Drugs? & $2.3 \%$ & $0 \%$ \\
\hline Place to stay? & $2.3 \%$ & $0 \%$ \\
\hline Have you had sex with a partner who used IV drugs & $4.7 \%$ & $0 \%$ \\
\hline Have you had sex after using alcohol/drugs? & $27.9 \%$ & $34.9 \%$ \\
\hline \multicolumn{3}{|l|}{ Have you had sex with someone you have known for } \\
\hline less than 24 hours? & $41.9 \%$ & $25.6 \%$ \\
\hline Have you been pressured into unwanted sex or been raped? & $14.0 \%$ & $4.7 \%$ \\
\hline \multicolumn{3}{|l|}{ Who was your first sexual partner } \\
\hline A regular partner or spouse & $90.7 \%$ & $97.7 \%$ \\
\hline Casual partner & $7.0 \%$ & $2.3 \%$ \\
\hline Rape & $2.3 \%$ & $0 \%$ \\
\hline Other - please specify & $0 \%$ & $0 \%$ \\
\hline Age in years at time of first sexual encounter & 16.5 & 16.2 \\
\hline
\end{tabular}

*Significant at $\mathrm{p}<0.001$
The AIDS Risk Behaviour Knowledge Questionnaire (ARBKQ) was developed to determine participants' practical understanding of the transmission of HIV, the disease itself, risk behaviour and risk reduction strategies. Table 2 contains the full questionnaire and results.

Out of the eleven original ARBKQ-items significant knowledge deficits could be demonstrated in the patient group for five items (percentage indicating number of participants answering the item correctly (P) vs (C)): "Most people become ill soon after getting the AIDS virus" $44.2 \%$ vs $93 \%$; "Only gay (homosexual) men get AIDS" $67.4 \%$ vs $97.7 \%$; "You can get the AIDS virus after only one sexual contact" $60.5 \%$ vs $95.3 \%$; "People who can give you the AIDS virus always look sick" $51.2 \%$ vs $95.3 \%$ (all four items p<0.0001); and "Sex with someone who has used an injectable drug creates a risk for AIDS" $67.4 \%$ vs $93 \%$ ( $\mathrm{p}<0.003$ ).

The patient group were significantly more knowledgeable on only one item "You must have many sex partners to get AIDS" $62.3 \%$ vs. $23.3 \%$ $(\mathrm{p}<0.0001)$. No significant knowledge difference could be demonstrated for the remaining five original items. specifically included for the purpose of
With regards to the item 
Table 2: Correct Responses To Aids Risk Behaviour Knowledge Questionnaire

\begin{tabular}{|c|c|c|c|}
\hline & \multicolumn{3}{|c|}{ Percent that answered correctly } \\
\hline & Patients & Controls & p-value \\
\hline $\begin{array}{l}\text { Most people become sick quickly after } \\
\text { getting the AIDS virus }\end{array}$ & $44.2 \%$ & $93 \%$ & $<0.0001 *$ \\
\hline Women can't get AIDS if they only have sex with men. & $74.4 \%$ & $55.8 \%$ & NS \\
\hline People who can give you the AIDS virus always look sick. & $51,2 \%$ & $95.3 \%$ & $<0.0001 *$ \\
\hline Men can't get AIDS if they only have sex with women. & $74.4 \%$ & $55.8 \%$ & NS \\
\hline Washing after sex stops AIDS. & $81.4 \%$ & $95.3 \%$ & 0.05 \\
\hline Only gay (homosexual) men get AIDS & $67.4 \%$ & $97.7 \%$ & $<0.0001 *$ \\
\hline You must have many sex partners to get AIDS. & $62.8 \%$ & $23.3 \%$ & $<0.0001 *$ \\
\hline $\begin{array}{l}\text { Sex with someone who has used injected } \\
\text { drugs creates risk for AIDS. }\end{array}$ & $67.4 \%$ & $93 \%$ & $0.003^{*}$ \\
\hline Using condoms (rubbers) can help prevent AIDS. & $90.7 \%$ & $88.4 \%$ & NS \\
\hline Unborn babies can get AIDS from their mothers. & $86.0 \%$ & $97.7 \%$ & NS \\
\hline You can get the AIDS virus through one $:$ exual contact. & $60.5 \%$ & $95.3 \%$ & $<0.0001 *$ \\
\hline
\end{tabular}

*Significance at $\mathrm{p}<0.05$; NS $=$ Non-signif cant

our study - "You can get AIDS from the depot antipsychotic injection" - $100 \%$ of controls knew the answer to be false whereas 5 patients incorrectly gave the answer as true. Out of the original eleven, the mean total items correct for the patients against controls was 7.6 (1.68) vs. $8.9(1.47), \mathrm{p}<0.001$

\section{DISCUSSION}

Our study, was the first of its kind on a South African schizophrenia group and the results confirmed an impaired general level of HIV/AIDS risk behaviour knowledge in this population in comparison to that of a control group. With regard to the original eleven items on the $A R B K Q$, significant patient knowledge-deficits could be demonstrated for five items in comparison to the controls that only demonstrated a significant knowledge-deficit on one item. Importantly this was also the item that the control group had the lowest total correct score on.

Furthermore $90 \%$ of the control group answered at least $70 \%$ of the ARBKQ-items correctly in comparison to the more than $40 \%$ of the patient group who answered less than $70 \%$ of the ARKBQ-items correctly. Especially worrying was the fact that many patients did not believe that you could contract HIV after only one sexual contact or that using injectable drugs increased a risk for HIV. Also disturbing was the fact that five patients were of the belief that the depot antipsychotic injection placed them at risk for contracting AIDS.
With regard to participation in sexual behaviours, no statistically significant differences could be demonstrated between the two groups, but it is important to note that while none of the control group admitted to having had sex in exchange for favours (money, drugs, or accommodation) or with a partner who had used injectable drugs, a small percentage of the patient group admitted to having engaged in each of these behaviours.

Although media campaigns and educational interventions are used to alert the general population to HIV/AIDS risks and risk reduction measures, it would be valid to question how much of this information reaches the chronically mentally ill patient.

A literature search revealed two studies focussing specifically on the outcome of educational interventions in populations with severe mental illness. Kalichman et al ${ }^{15}$ recruited 52 participants of which $61 \%$ had a clinic chart diagnosis of schizophrenia. The patients were randomly assigned to either an AIDS prevention program or to a waiting-list group who later received the same intervention. The relatively brief, skillsfocussed AIDS prevention program significantly reduced rates of unprotected sexual intercourse and increased the use of condoms as evaluated at a one month follow-up.

Kelly et al $^{16}$ reached similar conclusions. A total of 104 chronically mentally ill patients were randomly assigned to one of three interventions: a single AIDS education session, a sevensession group intervention using a cognitive behavioural approach or a seven-session group intervention that combined the cognitive-behavioural intervention approach with advocacy training. The authors concluded that although all participants exhibited a decrease in risk behaviours, the group with advocacy training reported greater reductions in rates of unprotected sex and had fewer sexual partners at follow-up.

In the American Psychiatric Association's practice guidelines it is suggested that a risk behaviour assessment should be part of every psychiatric evaluation to identify at risk individuals. ${ }^{17}$ In order to achieve this, psychiatrists must have adequate knowledge of specific sexual risk behaviours and be able to elicit the information, using clear vocabulary and keeping the cultural beliefs of the patient in mind. Following their meta-analysis, Meade and Sikkema ${ }^{5}$ support this view, suggesting that a risk assessment, routine HIV testing, condom availability and clinician training should form part of the agenda for HIV/STD prevention.

The results of our study confirm previously reported international data showing that patients with severe mental illness are not only sexually active but they partake in HIV/AIDS high risk behaviours. In comparison with a matched control group our schizophrenia population demonstrated significantly decreased overall HIV/AIDS risk behaviour knowledge. Therefore, current AIDS education strategies seem not to be reaching this particular vulnerable group.

The strengths of our study included the use of a culturally homogenous group as well as a structured interview (also to confirm diagnosis) that was administered in the participants' home language. Importantly, although the patient group were at different stages of illness, none of them was acutely behaviourally disturbed at the time of the interview; they also had to be able to provide accurate demographic information and concentrate for the duration of the full structured interview.

Not only did our findings confirm the need for education strategies 
specifically aimed at the seriously mentally ill but areas of deficit that need particular focus were also highlighted. Amongst others, psycho-education with regards to the depot antipsychotic injection should be prioritized in order to prevent non-compliance due to ignorance.

As part of its' HIV/AIDS strategy - treating 3 million by 2005: making it happen - the WHO has declared that "special attention will be given to protecting and serving vulnerable groups in prevention and treatment programmes". ${ }^{18}$ This suggests that patients with schizophrenia should be a target group when developing AIDS prevention programmes. Taking this into account and in light of our findings, it would therefore seem that South African mental health professionals not only have a unique opportunity but also an obligation from an ethical point of view to either provide or at least advocate an appropriate comprehensive HIV/AIDS treatment which includes prevention strategies (primary, secondary and tertiary) for their clients.

\section{ACKNOWLEDGEMENT}

This study received financial support in the form of Harry and Doris Crossley Foundation Grant and Lundbeck Community Research Grant.

\section{REFERENCES}

1. World Health Organization.WHO HIV/ AIDS strategy under the spotlight. Bulletin of the WHO. 2004; 82: 474 477.

2. Dorrington RE, Bradshaw D, Johnson L, Budlender D. The Demographic Impact of HIV/AIDS in South Africa.
National indicators for 2004. Cape Town: Centre for Actuarial Research, South African Medical Research Council and Actuarial Society of South Africa; 2004.

3. Sullivan G, Koegel P, Kanouse DE, Cournos F, McKinnon K, Young AS, et al. HIV and people with serious mental illness; the public sector's role in reducing HIV risk and improving care. Psychiatric Services. 1990; 50: 648 652.

4. Brady SM, Carman EH. AIDS risk in the mentally ill: clinical strategies for prevention. In: New directions for mental health services. Goldfinger SM (Editor) San Francisco: Jossey Bass; 1990.

5. Meade CS, Sikkema KJ. HIV risk bchaviour among adults with severe mental illness: A systematic review. Clinical Psychology Review. 2005; 25: $433-457$.

6. Gottesman II, Groome CS. HIV/AIDS Risks as a consequence of schizophrenia. Schizophrenia Bulletin. 1997; 23: $675-684$.

7. Aizenberg D, Zemishlany Z, DorfmanEtrog P, WeizmanA. Sexual dysfunction in male schizophrenic patients. Journal of Clinical Psychiatry. 1995; 56: 137 141.

8. Kalichman SC, Kelly JA, Johnson JR, Bulto M. Factors associated with risk for HIV infection among chronic mentally ill adults. Journal of Psychiatry. 1994; 151: 221- 227.

9. Kelly JA, Murphy DA, Bahr GR, Brasfield TL, Davis DR, Hauth AC, et al. AIDS/HIV risk behaviour among the chronic mentally ill. Am $J$ Psychiatry. 1992; 149: 886 - 889 .

10. American Psychiatric Association. The diagnostic and statistical Manual of Mental Disorders, Fourth edition. Washington DC. American Psychiatric Press; 1994.

11. Nurnberger JI, Jr., Blehar MC, Kaufmann CA, York-Cooler C, Simpson
SG, Harkavy-Friedman J, et al. Diagnostic interview for genetic studies. Rationale, unique features, and training. NIMH Genetics Initiative. Arch Gen Psychiatry. 1994; 51: 849-859.

12. Kelly JA, Murphy D, Roffman R, Solomon L, Winett R, Stevenson L, et al. AIDS/HIV risk behaviour among gay men in small cities: findings of a 16-city national sample. Archives of Internal Medicine. 1999; 152: 2293-2297.

13. McKinnon K, Cournos F, MeyerBahlburg HFL, Guido JR, Caraballo LR, Margoshes ES, et al. Reliability of sexual risk behaviour interviews with psychiatric patients. American Journal of Psychiatry 1993; 150: 972 - 974.

1. Kelly JA, St Lawrence JS, Hood HV, Brasfield TL. An objective test of AIDS risk behaviour knowledge: scale development, validation, and norms. Journal of Behaviour Therapy and Experimental Psychiatry. 1989; 20: 3 $227-234$.

15. Kalichman SC, Sikkema KJ, Kelly JA, Bulto $M$. Use of a brief behavioural skills intervention to prevent HIV infection among chronic mentally ill adults. Psychiatric Services. 1995; 46: $275-280$,

16. Kelly JA, McAuliffe TL, Sikkema KJ, Murphy DA, Somlai AM, Mulry G, et al. Reduction in risk behaviour among adults with severe metal illness who learned to advocate for HIV prevention. Psychiatric Services. 1997; 48: 1283 1288.

17. American Psychiatric Association. Work Group on HIV/AIDS. Practice guideline for the treatment of patients with HIV/AIDS. American Journal of Psychiatry. 2000; 157 (Suppl): 1 - 62.

18. World Health Organization. Treating 3 million by 2005: making it happen: the WHO strategy: the WHO and UNAIDS global initiative to provide antiretroviral therapy to 3 million people with HIV/ AIDS in developing countries by the end of 2005. WHO Library; 2003. 